\title{
Experimental Investigation of Performance and Emission Characteristics of IDI Diesel Engine Using Homogenized Water in Bio-Diesel Emulsion
}

\author{
Zainal Ambri Abdul Karim ${ }^{1,}$, and Mohammed Yahaya Khan ${ }^{1}$ \\ ${ }^{1}$ Department of Mechanical Engineering, Universiti Teknologi PETRONAS, 32610 Bandar Seri \\ Iskandar, Perak Darul Ridzuan, Malaysia.
}

\begin{abstract}
Water in diesel emulsion when used as fuel in diesel engine has shown simultaneous reduction in both nitrogen oxides and particulate matters. However, when water in bio-diesel emulsion is used, the effect of simultaneous reduction of nitrogen oxides and particulate reduction is not achieved. The current study aims at investigating the diesel engine performance and exhaust emissions using water in bio-diesel fuel prepared by a homogenizer that produced micro-water particles in the emulsion. A $1.8 \mathrm{~L}$ indirect injection diesel engine was operated using bio-diesel fuel which contains $95 \%$ diesel and 5\% palm oil methyl ester, mixed with 5\%, $10 \%$ and $20 \%$ by volume of water. Engine testing was conducted at full load condition with the engine speeds ranges from 1000 to $4000 \mathrm{rpm}$. Torque, engine speed and fuel consumption were measured along with emissions of $\mathrm{NO}_{x}, \mathrm{CO}, \mathrm{CO}_{2}, \mathrm{HC}, \mathrm{O}_{2}$. The results showed small reduction in brake power, $1.4 \%$ and $2.1 \%$ for WBDE-5 and WBDE-10 respectively, at maximum torque. While, reduction in exhaust gas temperature, $\mathrm{CO}_{2}$ and smoke opacity for all the tested emulsions were exhibited. On the other hand, $\mathrm{NO}_{\mathrm{x}}$ was found to increase with increase in water contents due to the higher oxygen content in the bio-diesel fuel. WBDE-20 showed the worst efficacy due to having water content of $20 \%$ by volume.
\end{abstract}

\section{Introduction}

Diesel engines are preferred over the gasoline engines because of their robustness, fuel economy and high power output either in automobiles or in industrial applications. However, diesel fuel is considered as a major air polluting source especially for particulate matter (PM) and Nitrogen Oxides $\left(\mathrm{NO}_{\mathrm{X}}\right)$ [1]. Water in diesel emulsion has been proven to be a promising alternative fuel to provide clean and renewable fuel source. Out of several methods available for the introduction of water in to the combustion chamber, emulsified diesel fuel has been widely accepted practice for its efficacy in reducing both NOx and PM, and also it does not require any engine modification. Emulsified diesel fuel is characterised by the micro-water particles encapsulated in the diesel fuel with the presence of surfactant or emulsifier. It has

* Corresponding author: ambri@utp.edu.my 
been found that when WiDE is used as fuel, the decrease in the temperature of the combustion products causes the reduction in $\mathrm{NO}_{\mathrm{x}}$. Also the presence of water in the fuel seems to reduce the rate of formation of soot particles. The occurrence of micro explosion during combustion is often referred as the reason behind exhaust emission reductions of emulsified fuel. Micro explosion is accomplished due to the difference in the volatility between the water and diesel. Micro-water particles in the emulsion droplets reach the superheated state much earlier than diesel fuel which in turn leads to secondary atomization of the droplets, resulting in better air-fuel mixture and hence better combustion is achieved. WiDE is capable of overcoming the traditional trade off by reducing simultaneously both NOx and PM [2]. Outcomes of various studies on WiDE as fuel claimed that NOx has been reduced. When WiDE was tested on multi cylinder industrial diesel engine, a maximum of $37 \%$ reduction in NOx has been reported under steady state operation [3]. Another study with a single cylinder diesel engine claimed that $10 \%$ and $25 \% \mathrm{NO}_{\mathrm{x}}$ reduction has been achieved with $10 \%$ and $20 \%$ water content respectively [4]. With a lower injection pressure, Maiboom et al. [5] reported NOx reduction between 30-50\% using a 4 cylinder, HSDI diesel engine. Park et. al [6] reported $11.6 \%$ reduction in NOx was achieved when tested on 6- cylinder TCI diesel engine, while $18-20 \%$ NOx reduction was reported by Samec et al. [7] with water content of 10 to $15 \%$. With a $6 \%$ water content WiDE, a $24 \%$ reduction in NOx was reported by Gonguntla et al. [8]. Many other experimental studies under different testing conditions also indicated that achievable NOx reductions [9-10]. As for PM, at low load engine testing conditions a reduction of 94\% was reported [5] and approximately 34\% PM reduction was achieved [6]. On a separate study by Barnaud et al. [9] and Matheaus et al. [10], a drop of 50\% and 16\% of PM was observed, respectively.

As a penalty, the engine power and torque were found to decreased slightly when using WiDE as as fuel to achieve the emission reduction $[2,3,11,12]$. This reduction is attributed to the presence of water which does not possess any calorific value. Abu-Zaid [13] observed an increase in engine torque and power as the water content in WiDE increases. Also an increase in brake thermal efficiency for WiDE with $20 \%$ water has been reported from other studies $[2,3,13,14]$. On the other hand, most of the researchers reported that specific diesel for the same power output [2]. An increase of 22- $26 \%$ in sfc was mentioned by Maiboom et al. [5], while Nadeem et al. [11] reported a $15 \%$ increase of sfc, while $26 \%$ increase in sfc has been reported by [3]. Despite of different engine setups and testing methodologies, there was a common agreement that simultaneous reduction of NOx and PM is achievable with WiDE as fuel.

In all the previous studies on WiDE in diesel engine combustion, the preparation of emulsions was either by using neat diesel, low grade diesel or Ultra Low Sulfur Diesel (ULSD). Very little information is available on the use of bio-diesel as the base fuel for the emulsion. In the present study the emulsions were prepared using bio- diesel fuel which contains 95\% diesel and 5\% palm oil methyl ester. The experimental work aims to ascertain the effect of homogenized water in bio-diesel emulsion (subsequently, abbreviated as WBDE) on engine performance and exhaust emissions with three different percentage of water content, i.e. 5, 10 and $20 \%$. The testing was carried out at engine full load condition for seven different engine speeds. The exhaust gas emissions such as $\mathrm{NOx}, \mathrm{CO}, \mathrm{CO}_{2}, \mathrm{HC}, \mathrm{O}_{2}$ and smoke opacity were measured and analyzed in addition to the engine torque, brake power and bsfc.

\section{Materials and Methods}

Three blends of water in bio-diesel emulsions (WBDE) were prepared with $2 \%$ blend of commercially available surfactants. B5 diesel which contains $95 \%$ diesel and 5\% palm oil 
methyl ester was used to produce the emulsion. In order to achieve emulsion droplet size at micro size level and to ensure uniform distribution, the emulsion was made to pass through a homogenizer having a stator and a rotor spaced at 50 microns gap with a rotating speed of $3000 \mathrm{rpm}$.

The process was repeated to ensure emulsion homogeneity. The WBDE was visualized at $400 \mathrm{X}$ magnification using digital microscope and the micro- water particles in the emulsion droplets were found to be uniformly distributed and in order of size less than 2.0 $\mu \mathrm{m}$. The WBDE is considered stable when there was no observable separation for a period of 336 hours. Physical properties of B5 diesel and the WBDE are tabulated in Table 1. Anton Paar Micro viscometer Lovis 2000ME and density meter DMA 4500M were used to measure the viscosity and density of WBDE and B5 diesel. Calorific values of the fuels were obtained using Leco AC-350 bomb calorimeter which was calibrated using standard benzoic acid as standard. Chemical characteristics were analysed using CHNS analyser.

The schematic illustration of the experimental setup is shown in Figure 1. The experiments were performed on a FORD XLD 418 IDI engine and some of the important specifications of the engine is given in Table 2. Separate tanks were used to store B5 diesel and WBDE. There were no modifications made on either engine or injection pump setting. The engine was coupled with an eddy current dynamometer rated at $150 \mathrm{~kW}$ between 2800 and $8000 \mathrm{rpm}$ and a maximum torque rating of $500 \mathrm{Nm}$. Autotest IV engine control unit was used to control and for data management. In addition, Autochek exhaust gas analyzer capable of measuring $\mathrm{NOx}, \mathrm{CO}_{2}, \mathrm{CO}, \mathrm{HC}$ and $\mathrm{O}_{2}$ was used to measure the combustion exhaust gases. A smoke opacity meter combined with the analyzer with an accuracy scale range of $+/-2 \%$ was employed to measure the exhaust smoke.

Table 1. Physical properties of WBDE samples

\begin{tabular}{|l|c|c|c|c|c|c|c|}
\hline Sample & $\begin{array}{c}\text { Density } @ 20^{\circ} \mathrm{C} \\
\left\{\mathrm{kg} / \mathrm{m}^{3}\right\}\end{array}$ & $\begin{array}{c}\text { Viscosity } a 40^{\circ} \mathrm{C} \\
\left\{\mathrm{mm}^{2} / \mathrm{s}\right\}\end{array}$ & $\begin{array}{c}\text { Calorific Value } \\
\{\mathrm{J} / \mathrm{g}\}\end{array}$ & $\begin{array}{c}\text { Carbon } \\
\%\{\mathrm{w} / \mathrm{w}\}\end{array}$ & $\begin{array}{c}\text { Hydrogen } \\
\%\{\mathrm{w} / \mathrm{w}\}\end{array}$ & $\begin{array}{c}\text { Nitrogen } \\
\%\{\mathrm{w} / \mathrm{w}\}\end{array}$ & $\begin{array}{c}\text { Sulphur } \\
\%\{\mathrm{w} / \mathrm{w}\}\end{array}$ \\
\hline B5 Diesel & 842.90 & 3.409 & 42600 & 81.38 & 11.86 & 0.1013 & 0.126 \\
\hline WBDE-5 & 849.76 & 5.792 & 37460 & 80.32 & 16.42 & 0.1123 & 0.821 \\
\hline WBDE-10 & 854.44 & 6.146 & 36942 & 78.65 & 12.40 & 0.1930 & 0.679 \\
\hline WBDE-20 & 870.17 & 7.969 & 32481 & 68.94 & 9.73 & 0.2210 & 0.479 \\
\hline
\end{tabular}

Table 2. Engine specifications

\begin{tabular}{ll}
\hline Engine Type: Diesel,4-cylinder, Inline OHC, Indirect Injection \\
\hline Bore & $82.5 \mathrm{~mm}$ \\
\hline Stroke & $82 \mathrm{~mm}$ \\
\hline Cubic Capacity & $1753 \mathrm{cc}$ \\
\hline Compression Ratio & $21.5: 1$ \\
\hline Power output & $44 \mathrm{~kW}$ at $4800 \mathrm{rpm}$ \\
\hline Design Injection Pressure & $118 \mathrm{bar}$ \\
\hline Maximum Engine "No Load" Speed & $5350 \pm 50 \mathrm{rpm}$ \\
\hline Idle Speed & $850 \pm 50 \mathrm{rpm}$ \\
\hline
\end{tabular}




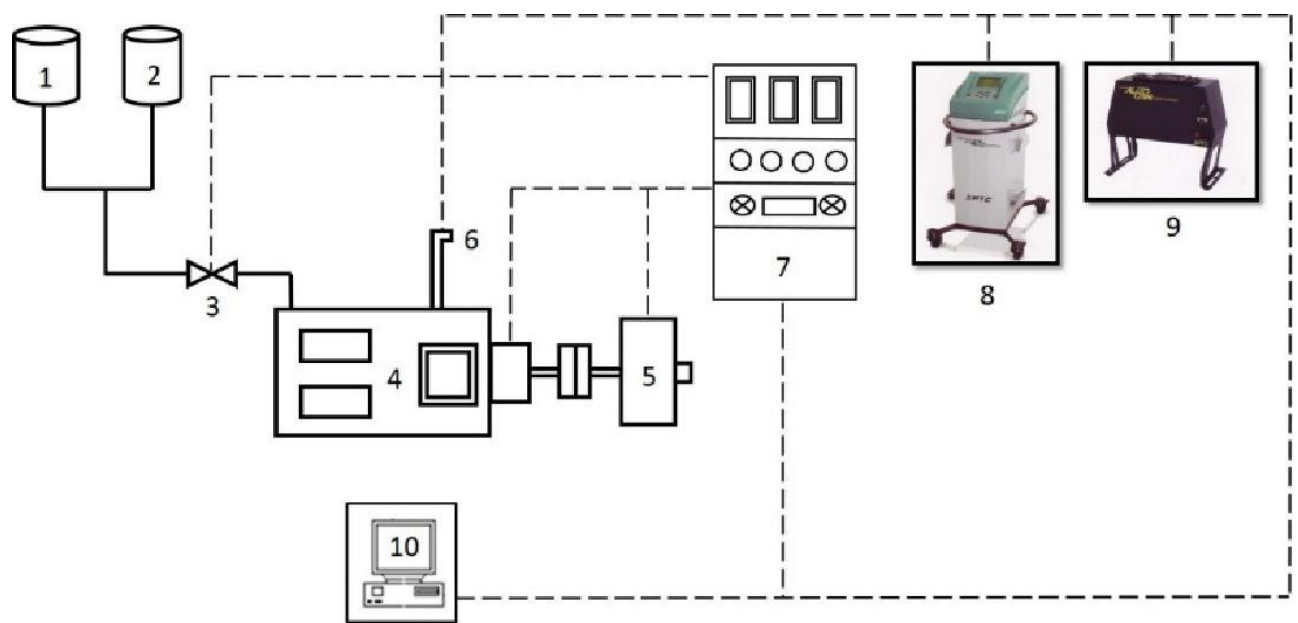

1. Diesel tank 2. Emulsion tank 3. Fuel flow meter 4. Engine 5. Eddy current Dynamometer 6. Exhaust pipe 7. Engine Control Unit 8. Gas Analyser 9. Smoke Opacity Meter 10. Computer

Fig. 1. Schematic drawing of the experimental setup

\subsection{Experimental Procedure}

Experiments were conducted at full load condition at seven different speeds starting from $1000 \mathrm{rpm}$ to $4000 \mathrm{rpm}$ at an interval of $500 \mathrm{rpm}$. Initial warm up of the engine was done using diesel and later switched to WBDE. Each speed was maintained until a stable condition is achieved before the required data was recorded. Exhaust emissions and smoke opacity were measured simultaneously.

\section{Results and Discussion}

The following sections discuss the results on the engine performance and exhaust gas emission measurements.

\subsection{Engine Torque}

The influence of WBDE on the engine torque output is plotted against the engine speed as shown in Figure 2. At initial speeds there were no significant difference noticed between B5 diesel and WBDE.

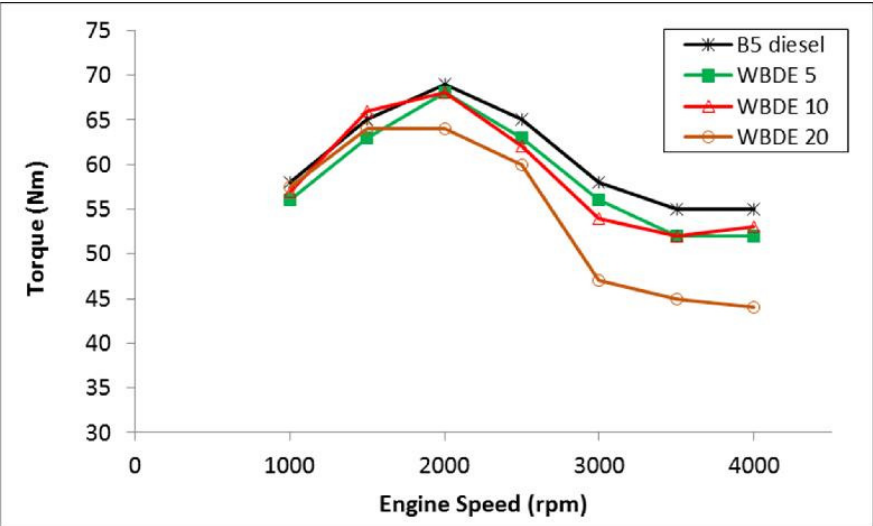

Fig. 2. Torque versus engine speed for B5 diesel and WBDE. 
All the tested fuels achieved the maximum torque at $2000 \mathrm{rpm}$, with WBDE-5 and WBDE-10 exhibiting similar torque with B5. Emulsion with 5\% water attained closest torque to that of diesel has been reported $[11,14]$. Only WBDE-20 showed lower torque at all engine speeds. The difference in the torque developed by B5 diesel and the emulsions is attributed to the fact that increase in water contents results in lower calorific value. WBDE-20 exhibited the lowest torque after $2000 \mathrm{rpm}$ with a maximum reduction of $20 \%$ compared to B5 diesel.

\subsection{Engine Brake Power}

The brake powers produced by all the emulsions in Figure 3 were less than B5 diesel at all engine speeds. However, the differences in brake power were small, especially at engine speed below $2000 \mathrm{rpm}$. The power produced by the emulsions compared to diesel decrease with increasing water content in the WBDE.

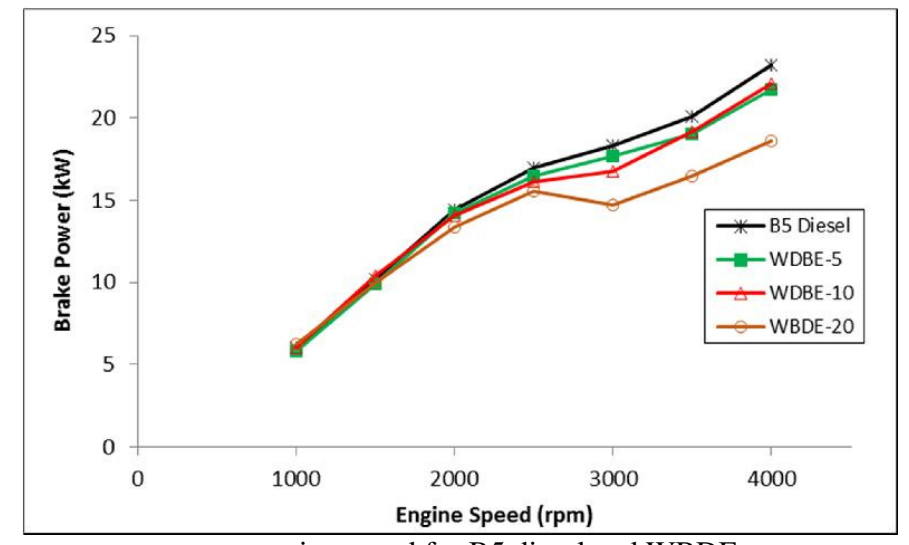

Fig. 3. Brake power output versus engine speed for B5 diesel and WBDE

The maximum power reduction with WBDE-5 was $6.4 \%$ which is in agreement with results obtained by Alahmer et al. [14], when emulsion with 5\% water was tested on a 4cylinder Di engine. For WBDE-10 the power reduction was found to be $8 \%$ which is similar to the findings of Barnes et al. [15] that for $10 \%$ water content by volume resulted in a power loss of 7-8\%. In the case of WBDE-20, a maximum of $19.8 \%$ loss in power was observed. Again, WBDE-20 showed the lowest brake power at all engine speeds, which indicates the limit to the amount of water that can be effectively added to the diesel fuel.

\subsection{Brake Specific Fuel Consumption}

The relationship between brake specific fuel consumption (bsfc) against engine speed for the B5 diesel and WBDE is plotted in Figure 4. 


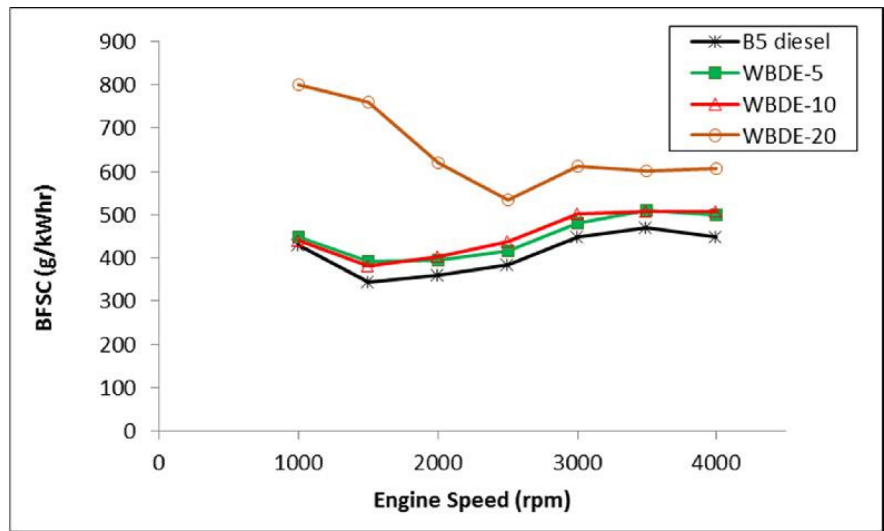

Fig. 4. bsfc versus engine speed for B5 diesel and WBDE

The bsfc initially decreases then increase as engine speed is increased. This is due to the fact that at lower speed, the engine consumes more fuel for the same output, and increased heat transfer to the cylinder wall and frictional losses. The figure shows the trend for fuel consumption which is similar to all emulsions except for WBDE-20. Specific fuel consumption for the WBDE is higher because of its lower calorific value and higher density compared to B5 diesel. Hence more fuel is required to maintain the engine speed at the given load. Similar trend of increase in bsfc has been reported by other researchers [2, 14, 16]. It is also observed that the bsfc for WBDE-5 and WBDE-10 are close to each other since the difference among these emulsions were small. WBDE-20 recorded the highest fuel consumption because of its lowest calorific value among the other emulsions.

\subsection{Exhaust Gas Temperature}

The relationship between the exhaust gas temperature and the engine speed at full load condition is plotted in Figure 5. The exhaust temperatures for all WBDE were found to be less than B5 diesel, with WBDE-5 exhibiting close values to B5 diesel. Increase in water content in WBDE proportionately reduces the exhaust temperature. Similar trends were reported by Abu-Zaid [13] when 5- $20 \%$ water content in the emulsion was tested on a single cylinder diesel engine. B5 diesel produced the highest exhaust temperature at all speeds. At the maximum speed and full load condition the exhaust temperature reduction for WBDE-5, WBDE-10 and WBDE-20 were $3.36 \%, 9.39 \%$ and $21.63 \%$ respectively. It is also observed that the difference in $\mathrm{CO} 2$ emission among the WBDE and B5 diesel was very small in the range of $0.46 \%$ to $0.6 \%$ only. 


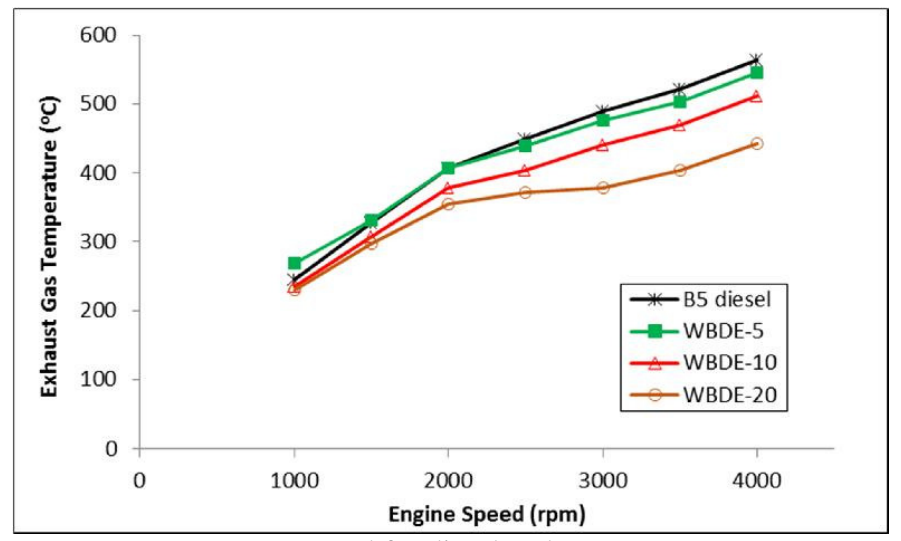

Fig. 5. Exhaust gas temperature versus speed for diesel and WBDE

\subsection{Carbon Monoxide (CO) Emission}

Figure 6 depicts $\mathrm{CO}$ emissions of $\mathrm{B} 5$ diesel and WBDE at full load at various engine speeds. The emissions of CO for both WBDE-5 and WBDE-10 showed higher than B5 diesel at the initial engine speed, while WBDE- 20 was lower than the diesel at all speeds. The probable reason for increasing $\mathrm{CO}$ trend is due to the lower combustion temperature at lower speeds, similar to the reports by $[12,17]$, since the oxidation of CO into CO 2is not possible when the temperature is lower than $1400 \mathrm{~K}$. As the engine speed increases and at higher combustion temperatures, $\mathrm{CO}$ tends to decrease. This finding indicates that WBDE might have better airfuel mixture, as was also observed by [18].

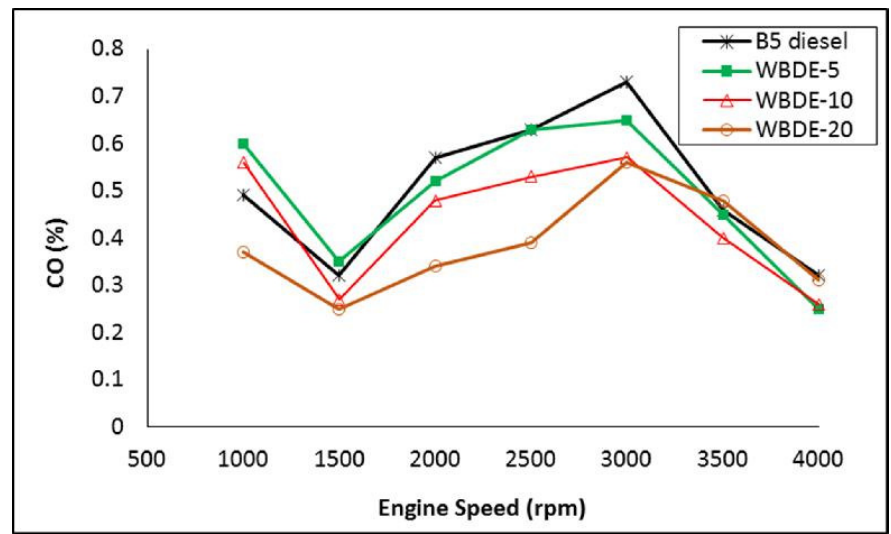

Fig. 6. $\mathrm{CO}$ emissions for $\mathrm{B} 5$ diesel and WBDE

\subsection{Carbon Dioxide (CO 2) Emission}

The CO 2 for B5 diesel and WBDE is plotted against the engine speed as shown in Figure 7. The CO 2 emissions increases with engine speed and for all WBDE fuels, CO 2 emissions were found to be less than B5 diesel. Both WBDE-5 and WBDE-10 followed a similar trend and the differences were insignificant. WiDE-20 produced lowest CO 2 between the speeds range of $1500 \mathrm{rpm}$ to $4000 \mathrm{rpm}$. 


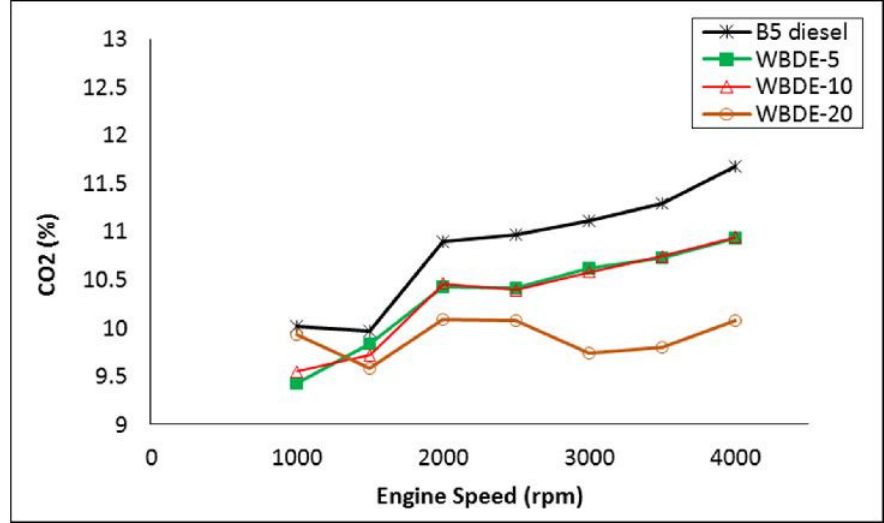

Fig. 7. $\mathrm{CO}_{2}$ emissions for $\mathrm{B} 5$ diesel and WBDE

\subsection{Nitrogen Oxide (NOx) Emission}

The emissions of NOx are plotted against engine speed for both B5 diesel and WBDE as shown in Figure 8.

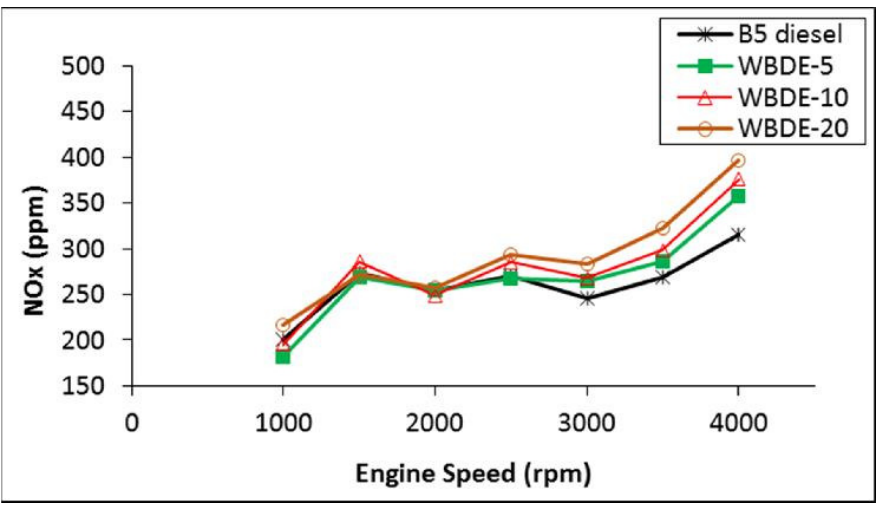

Fig. 8. NOx emissions for B5 diesel and WBDE

For engine speeds up to to $2000 \mathrm{rpm}$ there were no prominent difference between B5 diesel and WBDE, but as the speed increases, NOx showed an increasing trend. In this study, NOx was found to be increasing with the increase in the water content, although the exhaust temperature was reduced for all WBDE. This finding indicates that the additional oxygen content in the bio- diesel fuel might be the contributing factor in the NOx formation, which was also reported by [19]. At the maximum speed of $4000 \mathrm{rpm}$ the NOx for WBDE-20, WBDE-10 and WBDE-5 were 20.65\%, 16.22\% and 12.01\% higher the B5 diesel.

\subsection{Smoke Opacity of WBDE and B5 Diesel}

The smoke opacity of WBDE and B5 diesel are plotted in Figure 9. Smoke opacity for all the fuels decreased with engine speeds. The combustion of B5 diesel produced the highest opacity, whereas the WBDE showed decreasing trends, with more significant reduction for WBDE with higher water contents. The presence of water increases the ignition delay which resulted in better air fuel mixing which lead to improved combustion. In addition, more smoke reduction with WBDE is due to high oxygen content which increases the flame speed 
during the air fuel interactions [20]. The finding proves that WBDE can significantly reduce the emissions of smoke from a diesel engine.

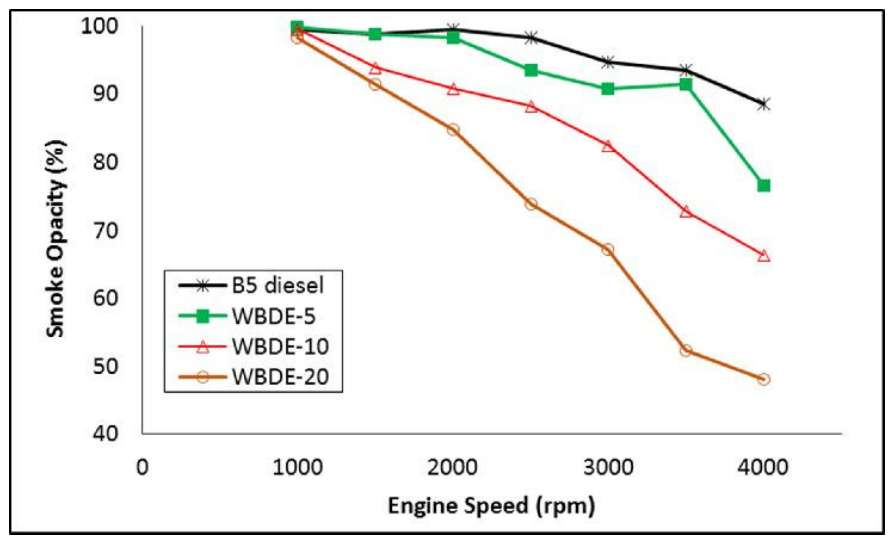

Fig. 9. Smoke opacity for B5 diesel and WBDE

\section{Conclusions}

Homogenized water in diesel emulsion (WiDE) with 5\%, $10 \%$ and $20 \%$ of water content was tested on an IDI diesel engine without any modification. The current study found that the presence of water in WBDE leads to small loss in torque and brake power, with minor increased in brake specific fuel consumption. The advantage of using WBDE as alternative fuel is exemplified by the reduction of exhaust gas temperature and significant reduction in smoke emissions. Contradictorily, increase in NOx was observed with increase in water contents of WBDE due to the use of bio-diesel fuel.

\section{References}

1. P. Brijesh P and Sreedhara, Int. J Automotive Tech. 14: 195-206 (2013).

2. M. Fahd E. A, Y. Wenming, P. Lee, S. Chou and C. R. Yap, App. Energy. 102:1042-1049 (2013).

3. J. Ghojel, D. Honnery, and K. Al-Khaleefi, App. Thermal Eng. 26: 2132-2141 (2006).

4. K. Kannan and M. Udayakumar, ARPN J Eng and App Sci. 4: 59-62 (2009).

5. A. Maiboom and X. Tauzia, Fuel. 90: 3179-3192 (2000).

6. K. Park, I. Kwak I and S., KSME Int. J. 18: 2049-2057 (2004).

7. N. Samec, B. Kegl and R. W. Dibble, Fuel. 81: 2035-2044 (2002).

8. T. Gonguntla, R. Raine, L. Ramsey and T. Houlihan, Characteristics of Water-in-Diesel Emulsions in a Single Cylinder Compression Ignition Engine. ASME 2014 Int. Mech. Engg Congress and Exposition. (2014).

9. F. Barnaud, P. Schmelzle and P. Schulz. AQUAZOLETM: An original emulsified water-diesel fuel for heavy-duty application. SAE Technical Paper (2000).

10. A. C. Matheaus, T. W. Ryan, D. Daly, D. A. Langer and M. P. Musculus. Effects of PuriNOx ${ }^{\mathrm{TM}}$ Water-Diesel Fuel Emulsions on Emissions and Fuel Economy in a Heavy-Duty Diesel Engine. SAE Technical Paper (2002).

11. M. Nadeem, C. Rangkuti, K. Anuar, M. Haq, I. Tan and S. Shah, Fuel. 85: 2111-2119 (2006).

12. K. Subramanian, Energy Conv. and Mgt. 52:849-857 (2011).

13. M. Abu-Zaid, Energy Conv and Mgt. 45: 697-705 (2004).

14. A. Alahmer, J. Yamin, A. Sakhrieh and M. Hamdan, Energy Conv and Mgt. 51: 1708-1713 (2010). 
15. A. Barnes, D. Duncan, J. Marshall, A. Psaila, J. Chadderton and A. Eastlake, Evaluation of waterblend fuels in a city bus and an assessment of performance with emission control devices. SAE Technical Paper (2000).

16. C. Y. Lin and K. H. WangFuel. 83: 537-545 (2004).

17. X. Cui, A. Helmantel, V. Golovichev and I Denbratt. Combustion and Emissions in a Light-Duty Diesel Engine Using Diesel-Water Emulsion and Diesel-Ethanol Blends. SAE Technical Paper (2009).

18. A. M. Ithnin, M. A. Ahmad, M. A. A. Bakar, S. Rajoo and W. J. Yahya, Energy Conv. and Mgt. 90:375-382 (2015).

19. M. Rizwanul, M. A. Kalam, H. H. Masjuki and M. A. Wakil, RCS Advances. 4 (34): 17787-17796 (2014).

20. G. Kannan and R. Anand, Energy.36:1680-1687 (2011). 